\title{
Incidence and Risk Factors of Combined-Antiretroviral Therapy-Induced Hepatotoxicity among HIV Patients at the Bali District Hospital, Cameroon
}

YayahEmerencia Ngah, 1,2, ,*, Frederick Nchang Cho ${ }^{3,4,5, \pi}$, Bisong Shauna Etagha ${ }^{6,7, \&}$, Neh Gladys Fusi $^{8, \&}$, Neba Francisca ${ }^{9, \&}$, Mondinde George Ikomey ${ }^{10,11, \&}$, Njimona Ibrahim1,12, ฯ,*

${ }^{1}$ Dapartment of Medical Laboratory Sciences, Faculty of Health Sciences, Bamenda University of Science Technology (BUST), Cameroon.

${ }^{2}$ Department of Public Health, Faculty of Health Sciences, Texila American University, Georgetown, Cooperative Republic of Guyana.

${ }^{3}$ Department of Biochemistry and Molecular Biology, Faculty of Science, University of Buea, P. O. Box 63 Buea, Cameroon.

${ }^{4}$ Infectious Disease Laboratory, Faculty of Health Sciences, University of Buea, P. O. Box 63 Buea, Cameroon.

${ }^{5}$ Central African Network for Tuberculosis, HIV/AIDS and Malaria (CANTAM), University of Buea, Buea, Cameroon.

${ }^{6}$ Department of Biological Sciences, Faculty of Sciences, University of Bamenda, Cameroon.

${ }^{7}$ Dapartment of Medical Laboratory Sciences, Faculty of Health Sciences, University of Bamenda, Cameroon.

${ }^{8}$ Departmen of Public Health, Faculty of Health Sciences, University of Information Technology (ICT-U), Yaoundé, Cameroon.

${ }^{9}$ Laboratory Department, Holy Family Hospital Akum, Bamenda, Cameroon.

${ }^{10}$ Centre for the Study and Control of Communicable Diseases, Faculty of Medicine and Biomedical Sciences, University of Yaoundé I, Yaoundé, Republic of Cameroon.

${ }^{11}$ Department of Microbiology, Parasitology, Haematology and Infectious Diseases, Faculty of Medicine and Biomedical Sciences, University of Yaoundé 1, Yaoundé, Republic of Cameroon.

${ }^{12}$ IMPM, Ministry of Scientific Research Yaoundé, Cameroon.

*Corresponding Authors: emerenciayaya@gmail.com(YEN),njimona@yahoo.com(JI)

ORCIDs: 0000-0001-6468-5377 (YEN), 0000-0002-6105-6388 (FNC), 0000-0002-3112-9267 (BSE), 0000-0002-2479-0516 (GMI), 0000-0001-6776-9680 (NI) 


\section{Abstract}

Introduction: The incidence of hepatotoxicity is life-threatening and can result to an end-stage liver disease in long-term patients on combined antiretroviral therapy (cART). Our study sought to evaluate the incidence and predictors of cART-induced hepatotoxicity (CIH) among long term users on cART in a rural District hospital.

Methods: This was a hospital-based cross-sectional study in the Bali District Hospital. Spectrophotometric method was use for the quantitative measurement of alanine-aminotransferase (ALT) and aspartate-aminotransferase (AST) levels. Patients with elevations of both ALT and AST were considered $\mathrm{CIH}$. The Chi $\left(\chi^{2}\right)$ square test, ANOVA and Kaplan Meier log-ranked/ survival analyses were used to analyse the data.

Results: Of the 350 participants enrolled [156 (44.6\%) males and 194 (55.4\%) females], aged $43.87 \pm 0.79$ years (range $20-84$ years) included in this analysis, $26(4.4 \%)$ experienced moderate CIH. We observed 57 (16.3\%), 62 (17.7\%) and 238 (68\%) elevated levels ALT + AST, ALT and AST respectively. Two independent predictive factors of $\mathrm{CIH}$ were, the male sex and alcoholism during the study period.

Conclusion: The prevalence of CIH in HIV-infected patients in Bali was lower than that observed in previous studies. The duration of therapy had no influence on the frequency of $\mathrm{CIH}$. Alcoholism and smoking showed significant differences in the development of CIH.

\section{keywords: Hepatotoxicity, Combined Antiretroviral Therapy (cART),HIV/AIDS,}

Transaminases, Bali, Cameroon. 


\section{Introduction}

The human immune deficiency virus/ acquired immunodeficiency syndrome (HIV/AIDS) is a devastating infection that remains a public health problem in Sub-Saharan Africa, is caused by either of two lentiviruses: HIV-1 or HIV-2[1, 2].Of the 36.7 million persons living with HIV (PLWHIV), with an estimated 2.1 million new infections, representing a rate of 0.3 new infections per 1,000 uninfected people worldwide, 19 million (51.8\%) are in Sub-Saharan Africa[3, 4].In Cameroon, the incidence of adult HIV has fallen consistently from $7.7 \%$ in 1999 to $4.3 \%$ in 2013 but has remained high among female sex workers, with an estimated prevalence of $3.6 \%$ (range; $1.5-6.3 \%$ ) within the ten Regions[5]. Highly Active Anti-Retroviral Therapy (HAART) is a combination of antiretroviral drugs for the management of HIV/AIDS [6, 7].The first-line HAART recommended for use in Cameroon by the Ministry of Public Health (MOH) and the World Health Organization (WHO) areTenofovir /Lamivudine/ Efavirenz(TDF+3TC+EFV)[8, 9].

Although HAART and combination antiretroviral therapy (cART) constitute the most significant interventions that have changed the landscape of HIV-related morbidity and mortality, there are also challenges of adverse drug reactions leading to dose modifications, changes or treatment discontinuations [10-12].

Highly Active Anti-Retroviral Therapy (HAART)-associated hepatoxicity/ cART-induced hepatotoxicity $(\mathrm{CIH})$, arbitrarily defined as AST or ALT $>3 \mathrm{X}$ upper limit of normal (ULN) in the presence of symptoms, or serum AST or ALT $>5 \mathrm{X}$ ULN in the absence of symptoms, usually resolves without modification of therapy [13-18]. Hepatotoxicity, which is the most cited reason for the withdrawal of approved drugs, is damage caused by exposure to a drug or non-pharmacological agents[19], and is consequently associated with HAART/ cART[15, 20] especially nevirapine-based HAART [21] or efavirenz-based drug-induced liver injury [22]. In isolated instances, serious and life-threatening conditions may arise. 
Theclinical presentation of HAART/ cART-induced hepatotoxicity can range from mild asymptomatic increases in serum transaminases to overt liver failure $[15,23,24]$. Retrospective studies indicate that, the incidence of cART-related severe hepatotoxicity is approximately $10 \%$, and life-threatening events occur at a rate of 2.6 per 100 person years [25]. The incidence of druginduced hepatotoxicity in the general African population is estimated to fall between 1/100,000 and 20/100,000 [26]. Hepatotoxicity due to ART may be related to agents from a number of classes including nucleoside reverse transcriptase inhibitors (NRTIs), non-nucleoside reverse transcriptase inhibitors (NNRTIs) and protease inhibitors [27]. The severity of hepatotoxicity may range from transient elevations in transaminase levels to hepatic failure and death, via a variety of mechanisms such as direct cell stress and disturbances in lipid/ sugar metabolism and steatosis, as seen with PI [27]. Co-infection with hepatitis B virus (HBV) or hepatitis $\mathrm{C}$ virus (HCV) has consistently been associated with increased risk of ART-related hepatotoxicity [25]. Other risk factors associated with ART-related liver injury include pre-existing advanced fibrosis, pre-treatment of elevated ALT or AST, alcohol abuse, old age, female gender, first exposure to ART, significant increase in $\mathrm{CD}^{+}$cell count after ART initiation, concomitant tuberculosis medications and cocaine use [28].

While all antiretroviral drugs have some risks of hepatotoxicity, some are more implicated than others. The non-nucleoside reverse transcriptase inhibitors (NNRTI) typically cause either hypersensitivity reactions or direct drug toxicity and therefore have two peaks of onset: within days to weeks or several months after initiation [25].Nevirapine (NVP) is the NNRTI most associated with hepatotoxicity[21], though hypersensitivity reactions resulting in liver failure have been reported with the newer NNRTI etravirine.Efavirenz and stavudine can also cause hepatotoxicity but does so less frequently than NVP or etravirine[22].

Many studies have been carried out in Cameroon $[9,29,30]$ and out of Cameroon $[14,15,23,31$ 33] on hepatotoxicity but there is paucity data on HAART/ cART-inducedhepatotoxicity. 
The main objective of this study was to determine the incidence of hepatotoxicity and to assess the possible risk factors for developing cART-induced hepatotoxicity among PLWHIV at the Bali District Hospital.

\section{Material and Methods}

A retrospective study of HIV - infected patients was conducted to examine the incidence and predictors of cART-induced hepatotoxicity $(\mathrm{CIH})$.

\subsection{Study Area}

The study was conducted at the state-owned Bali District Hospital in the North West Region of Cameroon between December 2017 to January 2018. Bali District Hospital is found in Bali Sub Division of Mezam Division in the North West Region of Cameroon.

Bali has a population of about 37,103 inhabitants[34],which is made up of mostly indigenouspeople, with a considerable proportion of non-indigenes. The most predominant activity of the people of Bali is farming.

\subsection{Study Design and Population}

A retrospective cross-sectional study was designed to examine the incidence and predictors of CIH. Study participants were Persons living with HIV, who were on cART/ HAART.

Participants aged $\geq 18$ years and willingness to have HIV status confirmed from clinical records or by a point-of-care test were included in the study. Pregnant women, those younger than 18 years, those on unprescribed medications and severely sick persons were excluded from the study.Participants with $\mathrm{CD}^{+}>500$ cells $/ \mu \mathrm{L}$ and viral load $<500$ copies $/ \mathrm{mL}$ were excluded from this analysis. 
The sample size was calculated using the CDC-Epi Info ${ }^{\mathrm{TM}}$ 7.2.3.1 StatCalc software with the following characteristics: an estimated population size for Bali Health area of 37,103 inhabitants [34], expected frequency of persons living with HIV on ART in Bali of 50\%, accepted error margin of 5\%, design effect of 1.0 and one cluster. Thus, the CDC-Epi Info ${ }^{\mathrm{TM}}$ 7.2.3.1 StatCalc estimated minimum sample size was 380.A final sample of 389 participants were enrolled into the study and $350(89.9 \%)$ were included in this analysis.

\subsection{Data collection tool and Data Collection}

The instruments used for the collection of data were, a well-organised laboratory form and patients' files. Data collected for analysis was defined as; socio-demographic information (age, gender and marital/educational status) and transaminase (ALT and AST) concentrations. The transaminase concentrations were obtained by spectrophotometric measurements.

\subsection{Specimen Collection and analysis}

$3 \mathrm{~mL}$ of blood specimen was collected from each participant by venipuncture into $5 \mathrm{~mL}$ vacutainer dry test tubes and allowed to clot at room temperature. The specimens were latter centrifuged for five minutes at $2500 \mathrm{rpm}$, and the sera collected were assayed for ALT and AST according to manufacturers' instructions (Quimica, Italy).

Laboratory analysis:All the ALT and AST measurements wereperformed at the Bali District Hospital Laboratory.

Hepatotoxicity was defined based on biochemical measurements as an elevation in serum ALT and/ or AST from the normal following the International Consensus Criteria and also on previous studies $[15,19,23]$.The severity of the liver injury was indicated by category (graded) based on various enzyme levels (Grade 1/ Mild, Grade 2/ Moderate, Grade 3/ Severe, and Grade 4/ Acute Liver Failure) [6, 16]. 


\subsection{Statistical Analysis}

All data collected was entered into epi info 7.2.3.1 for analyses. The variables that presented associationswith the outcome after bivariate analyses were entered intomultivariate logistic regression model to identify independentpredictors of cART-induced hepatotoxicity (CIH). The probabilities of developing hepatotoxicity with duration of antiretroviral treatment were estimated by Kaplan Meier methods and log-ranktest was used to determine statistically significant association.The Statistical Package for the Social Sciences (SPSS), version 25.0 for windows (IBMCorp.released 2017) was used for the multivariate regression analysis as well as the Kaplan Meier survival analysis.

Univariate and multivariate Cox proportional hazards regressions, were performed to assess the predictors of cART-induced hepatotoxicity. The variables included in the multivariate model were those with either a theoretical importance or ones with a $p<0.05$ in theunivariable models.

\subsection{Ethical considerations}

The study was approved by the Regional Delegate of Public Health for the North West Region and the Higher Institute of Health Sciences of Bamenda University of Science and Technology (BUST) and was conducted in accordance with the Helsinki declaration [35]. An administrative clearance was obtained from the Director of the Bali District Hospital.All participants signed informed consent forms and all records were strictly confidential.

\section{Results}

\section{Socio-Demographic Characteristics}

A total of 350 patients [156 (44.6\%) males and 194 (55.4) females] aged $43.87 \pm 0.79$ years (range $20-84$ years), with a mean $( \pm \mathrm{SEM})$ duration of cART of $6.30 \pm 0.21$ years (range $0-13$ years), were included for analysis in this study. A majority $154(44 \%)$ of the study participants were in the 
bioRxiv preprint doi: https://doi.org/10.1101/2020.11.16.384339; this version posted November 16,2020 . The copyright holder for this preprint (which was not certified by peer review) is the author/funder, who has granted bioRxiv a license to display the preprint in perpetuity. It is made available under aCC-BY 4.0 International license.

age group $40-<60$ years old and most of them $148(42.3 \%)$ had at least the secondary education (Table 1).

Thirty-four males $(29.6 \%, \mathrm{~N}=57)$ and 23 females $(40.4 \%, \mathrm{~N}=57)$ among cases had cART-induced hepatotoxicity. Of the 350 study participants, $34(9.7 \% \%)$ were malnourished as defined by body mass index (BMI) of $<18.5 \mathrm{Kg} / \mathrm{m}^{2}, 77(22.0 \%)$ were overweight, $14(4.0 \%)$ were obese and $64.3 \%$ were eutrophic (normal). Most of the participants $223(63.7 \%)$ were married and just one-fifth $(20.0 \%)$ of them were farmers (Table 1$)$.

Table 1: Socio-demographic and Clinical Characteristics of patients with and without hepatotoxicity

\begin{tabular}{|c|c|c|c|c|c|c|}
\hline Variable & Subclass & $n(\%)$ & No hepatotoxicity & Hepatotoxicity & $\chi^{2} / \mathbf{F}$ & $p$-value \\
\hline \multirow[t]{4}{*}{ Age (Years) } & $20-<40 /$ Young & $138(39.1)$ & $118(40.3)$ & $19(33.3)$ & 2.017 & 0.365 \\
\hline & $40-<60 /$ Middle & $154(44.0)$ & $129(44.0)$ & $25(43.9)$ & & \\
\hline & $\geq 60 /$ Maturity & $59(16.9)$ & $46(15.7)$ & $13(22.8)$ & & \\
\hline & Age $(\bar{x} \pm \mathrm{SEM})$ & $43.87 \pm 0.79$ & $43.27 \pm 0.85$ & $46.91 \pm 2.05$ & 2.916 & 0.089 \\
\hline \multirow[t]{2}{*}{ Sex } & Male & $156(44.6)$ & $122(41.6)$ & $34(29.6)$ & 6.265 & $0.012 *$ \\
\hline & Female & $194(55.4)$ & $171(58.4)$ & $23(40.4)$ & & \\
\hline \multirow[t]{5}{*}{ BMI $\left(\mathrm{Kg} / \mathbf{m}^{2}\right)$} & Malnourished & $34(9.7)$ & $30(10.2)$ & $4(7.0)$ & 0.631 & 0.889 \\
\hline & Overweight & $77(22.0)$ & $64(21.8)$ & $13(22.8)$ & & \\
\hline & Obese & $14(4.0)$ & $12(4.1)$ & $2(3.5)$ & & \\
\hline & Eutrophic & $225(64.3)$ & $187(63.8)$ & $38(66.7)$ & & \\
\hline & $\mathrm{BMI}(\bar{x} \pm \mathrm{SEM})$ & $23.33 \pm 0.20$ & $23.28 \pm 0.22$ & $23.58 \pm 0.46$ & 0.307 & 0.580 \\
\hline \multirow[t]{3}{*}{ WHO HIV Stage } & Stage 1 & $117(33.4)$ & $99(33.8)$ & $18(31.6)$ & 9.026 & $0.011 *$ \\
\hline & Stage 2 & $155(44.3)$ & $137(46.8)$ & $18(31.6)$ & & \\
\hline & Stage 3 & $78(22.3)$ & $57(19.5)$ & $21(36.8)$ & & \\
\hline \multirow[t]{3}{*}{$\mathrm{CD4}^{+}(\mathrm{Cells} / \mu \mathrm{L})$} & $<500$ & $85(24.3)$ & $62(21.2)$ & $23(40.4)$ & 9.557 & $0.002 *$ \\
\hline & $\geq 500$ & $265(75.7)$ & $231(78.8)$ & $34(59.6)$ & & \\
\hline & $\mathrm{CD}^{+}(\bar{x} \pm \mathrm{SEM})$ & $665.25 \pm 20.68$ & $691.58 \pm 22.79$ & $529.91 \pm 45.32$ & 8.509 & $0.004 *$ \\
\hline \multirow[t]{5}{*}{$\begin{array}{l}\text { Viral Load } \\
\text { (Copies/mL) }\end{array}$} & $\mathrm{L} 40$ & $52(14.9)$ & $47(16.0)$ & $5(8.8)$ & 42.192 & $6.48 \times 10^{-4 *}$ \\
\hline & $<500$ & $6(1.7)$ & $0(0.0)$ & $6(10.5)$ & & \\
\hline & $\geq 500$ & $174(49.7)$ & $137(46.8)$ & $37(64.9)$ & & \\
\hline & TND & $118(33.7)$ & $109(37.2)$ & $9(15.8)$ & & \\
\hline & $\mathrm{VL}(\bar{x} \pm \mathrm{SEM})^{* *}$ & $\begin{array}{c}3.35 \times 10^{5} \pm \\
9.80 \times 10^{4}\end{array}$ & $\begin{array}{c}1.74 \times 10^{5} \pm \\
6.51 \times 10^{4}\end{array}$ & $\begin{array}{c}9.48 \times 10^{5} \pm \\
3.42 \times 10^{5}\end{array}$ & 12.057 & $0.001 *$ \\
\hline \multirow[t]{5}{*}{ cART regimen } & AZT/3TC/EFV & $32(9.1)$ & $22(7.5)$ & $10(17.5)$ & 8.024 & 0.091 \\
\hline & AZT/3TC/NVP & $60(17.1)$ & $51(17.4)$ & $9(15.8)$ & & \\
\hline & TDF/3TC/EFV & $68(19.4)$ & $56(19.1)$ & $12(21.1)$ & & \\
\hline & TDF/3TC/NVP & $33(9.4)$ & $26(8.9)$ & $7(12.3)$ & & \\
\hline & $\mathrm{TDF} / 3 \mathrm{TC}$ & $157(44.9)$ & $138(47.1)$ & $19(33.3)$ & & \\
\hline \multirow[t]{4}{*}{ Duration on cART } & $0-5$ years & $158(45.1)$ & $127(43.3)$ & $31(54.4)$ & 4.903 & 0.086 \\
\hline & $6-10$ years & $118(33.7)$ & $106(36.2)$ & $12(21.1)$ & & \\
\hline & $>10$ years & $74(21.1)$ & $60(20.5)$ & $14(24.6)$ & & \\
\hline & Duration $(\bar{x} \pm \mathrm{SEM})$ & $6.30 \pm 0.21$ & $6.30 \pm 0.23$ & $6.30 \pm 0.59$ & $2.9 \times 10^{-5}$ & 0.996 \\
\hline \multirow[t]{2}{*}{ Marital status } & Married & $223(63.7)$ & $188(64.2)$ & $35(61.4)$ & 0.157 & 0.692 \\
\hline & Single & $127(36.3)$ & $105(35.8)$ & $22(38.6)$ & & \\
\hline Alcohol & Yes & $25(7.1)$ & $15(5.1)$ & $10(17.5)$ & 11.106 & $0.001 *$ \\
\hline
\end{tabular}




\begin{tabular}{llccccc}
\multirow{5}{*}{ Smoking } & No & $325(92.9)$ & $278(94.9)$ & $47(85.2)$ & & $0.011^{*}$ \\
& Yes & $15(4.3)$ & $9(3.1)$ & $6(10.5)$ & 6.464 & \\
Education & No & $335(95.7)$ & $284(96.9)$ & $51(89.5)$ & & 0.956 \\
& Tertiary & $81(23.1)$ & $67(22.9)$ & $14(24.6)$ & 0.090 & \\
& Secondary & $148(42.3)$ & $124(42.3)$ & $24(42.1)$ & & \\
Occupation & Primary & $121(34.6)$ & $102(34.8)$ & $19(33.3)$ & & \\
& Unemployed & $32(9.1)$ & $27(9.2)$ & $5(8.8)$ & 0.405 & 0.982 \\
& Unskilled & $84(24.0)$ & $69(23.5)$ & $15(26.3)$ & & \\
& Farming & $70(20.0)$ & $58(19.8)$ & $12(21.1)$ & & \\
& Business & $68(19.4)$ & $57(19.5)$ & $11(19.3)$ & & \\
& Skilled & $96(27.4)$ & $82(28.0)$ & $14(24.6)$ & & \\
& Total & $\mathbf{3 5 0}$ & $\mathbf{2 9 3}(\mathbf{8 3 . 7})$ & $\mathbf{5 7 ( 1 6 . 3 )}$ & & \\
\hline
\end{tabular}

${ }^{*} p$-values with statistical significance, ${ }^{* *}$ has 180 instead of 350 respondents, $95 \%$ C.I.; $95 \%$ Confidence interval, AST; Aspartate aminotransferase, ALT; Alanine aminotransferase, BMI; Body Mass Index [Malnourished (BMI < 18.5), Eutrophic (18.5 $\leq \mathrm{BMI} \leq 24.9)$, Overweight $(25.0 \leq \mathrm{BMI} \leq 29.9)$, Obese (BMI $\geq 30.0)$ ], AZT; Zidovudine, TDF; Tenofovir, EFV; Efavirenz, 3TC; Lamivudine, NVP; Nevirapine, cART; Combined anti-retroviral therapy.

There was no significant difference as regards age, BMI, cART regimen and duration of therapy between cases and controls.

\section{Clinical and Biochemical Spectrum of Participants}

Majority $155(44.3 \%)$ of the study participants had WHO stage 2 HIV, $117(33.4 \%)$ had stage 1, while theremaining $78(22.3 \%)$ had stage 3 HIV.The mean $\left( \pm\right.$ SEM) $\mathrm{CD}^{+}$count was $529.91( \pm$ 45.32) and $691.58( \pm 22.79)$ for cases and controls, respectively.

Ten alcoholics $(17.5 \%, \mathrm{~N}=57)$ and six smokers $(10.5 \%, \mathrm{~N}=57)$ were among the cases who had CIH.

The mean $( \pm$ SEM) values of ALT and AST were $30.18( \pm 0.76) \mathrm{U} / \mathrm{L}$ and $49.52( \pm 1.06) \mathrm{U} / \mathrm{L}$ and were significantly higher amongst cases $[55.00( \pm 1.82) \mathrm{U} / \mathrm{L}$ vs $72.61( \pm 3.43) \mathrm{U} / \mathrm{L}]$ than controls $[25.35 \pm(0.46) \mathrm{U} / \mathrm{L}$ vs $45.03( \pm 0.85) \mathrm{U} / \mathrm{L}]($ Table 2$)$

Table 2 shows the prevalence of elevated liver enzymes in the five cART treatment groups. Patients on TDF/3TC, had the highest incidence19 (30.6\%) and $94(39.5 \%)$ of elevated ALT and AST respectively, followed by TDF/3TC/EFV with incidence of $15(24.2 \%)$ and $51(21.4 \%)$ of elevated ALT and AST respectively. However, the overall prevalence of hepatotoxicity in the five treatment groups for the two liver enzymes was $57(16.3 \%)$. 
Table 2: Bivariate analysis of cART association withelevated transaminases

\begin{tabular}{llcccccc}
\hline Transaminase & cART & Normal (\%) & Elevated (\%) & Total (\%) & $\overline{\boldsymbol{x}} \pm$ SEM & $\boldsymbol{\chi}^{2} / \mathbf{F}$ & $\boldsymbol{p}$-value \\
\hline \multirow{2}{*}{ ALT } & AZT/3TC/EFV & $22(7.6)$ & $10(16.1)$ & $32(9.1)$ & $39.13 \pm 2.87$ & 10.667 & $0.031^{*}$ \\
& AZT/3TC/NVP & $51(17.7)$ & $9(14.5)$ & $60(17.1)$ & $28.57 \pm 1.87$ & & \\
& TDF/3TC/EFV & $53(18.4)$ & $15(24.2)$ & $68(19.4)$ & $28.84 \pm 1.37$ & & \\
& TDF/3TC/NVP & $24(8.3)$ & $9(14.5)$ & $33(9.4)$ & $34.27 \pm 3.33$ & & \\
& TDF/3TC & $138(47.9)$ & $19(30.6)$ & $157(44.9)$ & $28.70 \pm 1.04$ & & \\
& ALT $(\bar{x} \pm$ SEM) & $25.35 \pm 0.46$ & $55.00 \pm 1.82$ & $30.18 \pm 0.76$ & $30.18 \pm 0.76$ & 503.41 & $1.36 \times 10^{-69 *}$ \\
& Total & $\mathbf{2 8 8}$ & $\mathbf{6 2}$ & $\mathbf{3 5 0}$ & & & \\
AST & AZT/3TC/EFV & $0(0.0)$ & $32(13.4)$ & $32(9.1)$ & $64.34 \pm 2.11$ & 21.631 & $2.37 \times 10^{-4 *}$ \\
& AZT/3TC/NVP & $21(18.8)$ & $39(16.4)$ & $60(17.1)$ & $54.42 \pm 3.34$ & & \\
& TDF/3TC/EFV & $17(15.2)$ & $51(21.4)$ & $68(19.4)$ & $48.97 \pm 1.83$ & & \\
& TDF/3TC/NVP & $11(9.8)$ & $22(9.2)$ & $33(9.4)$ & $52.00 \pm 5.11$ & & \\
& TDF/3TC & $63(56.3)$ & $94(39.5)$ & $157(44.9)$ & $44.35 \pm 1.22$ & & \\
& AST $(\bar{x} \pm$ SEM) & $45.03 \pm 0.85$ & $72.61 \pm 3.43$ & $49.52 \pm 1.06$ & $49.52 \pm 1.06$ & 126.30 & $3.28 \times 10^{-25 *}$ \\
& Total & $\mathbf{1 1 2}$ & $\mathbf{2 3 8}$ & $\mathbf{3 5 0}$ & & & \\
\hline
\end{tabular}

* $p$-values with statistical significance, cART; Combined anti-retroviral therapy, NV: ${ }^{\wedge}$ (ㅇ) of ALT; Up to 40 (32), NV of AST; Up to 38 (31) UI/L.

In all patients with cART-induced hepatotoxicity, $31(8.9 \%)$ had mild hepatoxicity while $26(7.4 \%)$ had moderate hepatotoxicity. Alanine aminotransferase (ALT) related hepatotoxicity 62/350 $(17.7 \%)$ was lower compared to AST related hepatotoxicity 238/350 (68\%).Alanine aminotransferase and AST hepatotoxicity were significantly $\left(p=0.031\right.$ vs $\left.p=2.37 \times 10^{-4}\right)$ associated with cART regimens (Table 2).

Results of the study indicated that there were five different cARTregimens (Figure 1; Table 1). A majority $157(44.9 \%)$ of the study participants were on TDF/3TC, followed by $19.4 \%$ of $\mathrm{TDF} / 3 \mathrm{TC} / \mathrm{EFV}, 17.1 \%$ of $\mathrm{AZT} / 3 \mathrm{TC} / \mathrm{NVP}, 9.4 \%$ of TDF/3TC/NVP and the least was $9.1 \%$ of $\mathrm{AZT} / 3 \mathrm{TC} / \mathrm{EFV}$. 


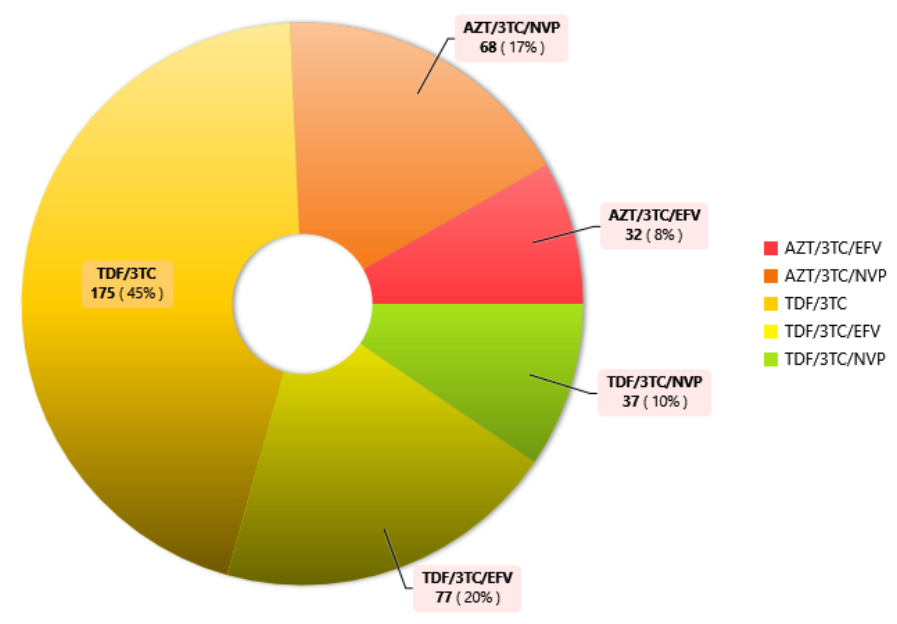

Figure 1: Regimens of combined ART

\section{Factors associated with cART-induced hepatotoxicity}

Age was categorized into three groups and there was no difference betweencases and controls between these age groups. The nutritional status (as assessed by BMI) of study participants seems to be good [mean $\left.( \pm \mathrm{SEM}), \mathrm{BMI} ; 23.33( \pm 0.20) \mathrm{kg} / \mathrm{m}^{2}\right]$.Cases were less likely to have malnutrition as compared to controls, 4 (7.0\%) vs 30 (10.2\%), respectively; $(p=0.889)$ (Table 1). The mean BMI was almost the same among cases as compared to controls, $23.58( \pm 0.46) \mathrm{kg} / \mathrm{m}^{2} \mathrm{vs} 23.28 \pm 0.22$ $\mathrm{kg} / \mathrm{m}^{2}$, respectively. The proportion of patients with WHO clinical stage 2 HIV was higher in the controlgroup137 $(46.8 \%, \mathrm{~N}=293)$ while in the cases group the number of WHO clinical stage 2 HIV was $18(31.6 \%, \mathrm{~N}=57)(p=0.011)$. Cases were also more likely to have lower $\mathrm{CD}^{+}$count as compared to controls; $23(40.4 \%, \mathrm{~N}=57)$ of cases and $62(21.2 \%, \mathrm{~N}=293)$ of controls had $\mathrm{CD}^{+}$ count less than 500 cell/ $\mu \mathrm{L}(p=0.002)$. Therefore;sex, WHO clinical stagesof HIV/AIDS, $\mathrm{CD}^{+} / \mathrm{VL}$, alcoholism and smoking were significantly associated withcART-induced hepatotoxicity from bivariate model analysis (Table 1).

Univariate analysis was also done using Cox Proportional hazard regression analysis for the variables in Table 3. Sex and alcohol consumption were observed to be predictors of cART-induced hepatotoxicity. In the multivariate model, the predictors of developing cART-induced hepatotoxicity 
include the male sex (Hazards Ratio $(\mathrm{HR})=1.6,95 \%$ C.I $=0.9-2.8$ ), the cART regimen $\mathrm{AZT} / 3 \mathrm{TC} / \mathrm{EFV}[\mathrm{HR}=2.5,95 \%$ C.I $=1.1-5.7]$ and alcohol consumption $[\mathrm{HR}=15.3,95 \%$ C.I $=$ $6.3-37.1]$

Table 3: Univariate and Multivariate Cox proportional regression analysis to show the risk factors for developingcART-induced hepatotoxicity

\begin{tabular}{|c|c|c|c|c|c|}
\hline & & & Univariate & & Multivariate \\
\hline Variable & Subclass & $p$-value & H.R (95\% C.I) & $p$-value & H.R (95\% C.I) \\
\hline \multirow[t]{3}{*}{ Age (Years) } & $20-<40 /$ Young & 0.11 & $0.6(0.3-1.1)$ & 0.26 & $0.6(0.3-1.4)$ \\
\hline & $40-<60 /$ Middle & 0.28 & $0.7(0.3-1.4)$ & 0.69 & $0.9(0.4-1.9)$ \\
\hline & $\geq 60 /$ Maturity & 0.28 & 1.0 & 0.46 & 1.0 \\
\hline \multirow[t]{2}{*}{ Sex } & Male & $2.9 \times 10^{-2 *}$ & $1.8(1.1-3.1) \dagger$ & $9.3 \times 10^{-2}$ & $1.6(0.9-2.8) \dagger$ \\
\hline & Female & Ref & 1.0 & Ref & 1.0 \\
\hline \multirow[t]{4}{*}{ BMI $\left(\mathrm{Kg} / \mathrm{m}^{2}\right)$} & Malnourished & 0.27 & $0.6(0.2-1.6)$ & 0.48 & $0.7(0.2-2.0)$ \\
\hline & Overweight & 0.90 & $1.0(0.5-1.8)$ & 0.91 & $1.0(0.5-1.9)$ \\
\hline & Obese & 0.13 & $3.1(0.7-13.2) \dagger$ & 0.31 & $2.2(0.5-10.1) \dagger$ \\
\hline & Eutrophic & 0.29 & 1.0 & 0.65 & 1.0 \\
\hline \multirow[t]{3}{*}{ WHO HIV Stage } & Stage 1 & 0.41 & $0.8(0.4-1.5)$ & 0.14 & $0.6(0.3-1.2)$ \\
\hline & Stage 2 & $3.2 \times 10^{-2 *}$ & $0.5(0.3-0.9)$ & $4.2 \times 10^{-2 *}$ & $0.5(0.2-1.0)$ \\
\hline & Stage 3 & 0.10 & 1.0 & 0.11 & 1.0 \\
\hline \multirow[t]{5}{*}{ cART } & $\mathrm{AZT} / 3 \mathrm{TC} / \mathrm{EFV}$ & $6.9 \times 10^{-2}$ & $2.0(0.9-4.4) \dagger$ & $2.4 \times 10^{-2 *}$ & $2.5(1.1-5.7) \dagger$ \\
\hline & AZT/3TC/NVP & 0.65 & $1.2(0.5-2.7) \dagger$ & 0.37 & $1.5(0.6-3.3) \dagger$ \\
\hline & TDF/3TC/EFV & 0.19 & $1.6(0.8-3.4) \dagger$ & 0.28 & $1.5(0.7-3.2) \dagger$ \\
\hline & TDF/3TC/NVP & 0.28 & $1.6(0.7-3.9) \dagger$ & 0.52 & $0.7(0.2-2.1)$ \\
\hline & $\mathrm{TDF} / 3 \mathrm{TC}$ & 0.39 & 1.0 & 0.13 & 1.0 \\
\hline \multirow[t]{2}{*}{ Alcohol } & Yes & $1.4 \times 10^{-10 *}$ & $12.6(5.8-27.4) \dagger$ & $1.5 \times 10^{-9 *}$ & $15.3(6.3-37.1) \dagger$ \\
\hline & No & Ref & 1.0 & Ref & 1.0 \\
\hline \multirow[t]{2}{*}{ Smoking } & Yes & $1.8 \times 10^{-2 *}$ & $0.4(0.2-0.8)$ & $7.8 \times 10^{-2}$ & $2.5(0.9-6.9) \dagger$ \\
\hline & No & Ref & 1.0 & Ref & 1.0 \\
\hline
\end{tabular}

H.R: Hazard ratio, 95\% C.I.: 95\% Confidence interval, ${ }^{*} p$-values with statistical significance, $\dagger$ Indicates likely groups.

The mean $( \pm$ SEM) time to onset of cART-induced hepatotoxicity was lower among patients with WHO clinical stage $3 \mathrm{HIV}$ as compared to WHO clinical stage 2 and WHO clinical stage $1 ; 2.61$ $( \pm 0.09), 2.83( \pm 0.05)$ and $2.78(0.05)$ patients, respectively $\left(\chi^{2}=7.108 ; p=0.029\right)$. Kaplan Meier analysis shows that patients with obesity $\left(\mathrm{BMI}>30 \mathrm{~kg} / \mathrm{m}^{2}\right)$ were likely to develop hepatotoxicity within $1.86( \pm 0.94)$ mean years while the malnourished, overweight and eutrophic patients were likely to develop hepatotoxicity in $2.89( \pm 0.08), 2.73( \pm 0.08)$ and $2.76( \pm 0.04)$ mean years of initiation of $\operatorname{cART}\left(\chi^{2}=1.4818 ; p=0.701\right)$ (Figure 2$)$.

The mean $( \pm$ SEM) time to onset of cART-induced hepatotoxicity among patients on the different treatments were $2.64( \pm 0.13), 2.82( \pm 0.07), 2.71( \pm 0.08), 2.82( \pm 0.11)$ and $2.78( \pm 0.05)$ respectively for AZT/3TC/EFV, AZT/3TC/NVP, TDF/3TC/EFV, TDF/3TC/NVP and TDF/3TC. Comparing the 
survival curves of hepatotoxicity, we observed that there is no statistically significant difference in occurrence rates of the participants in the various treatment groups and that the grouping has no significant influence on time of onset $\left(\chi^{2}=5.054 ; p=0.282\right)$ (Figure 2). The overall mean Survival Proportion (SP) and Standard Error (SE) with respect to the years of treatment were: $\mathrm{SP}=2.76$ and $\mathrm{SE}=0.034$ 

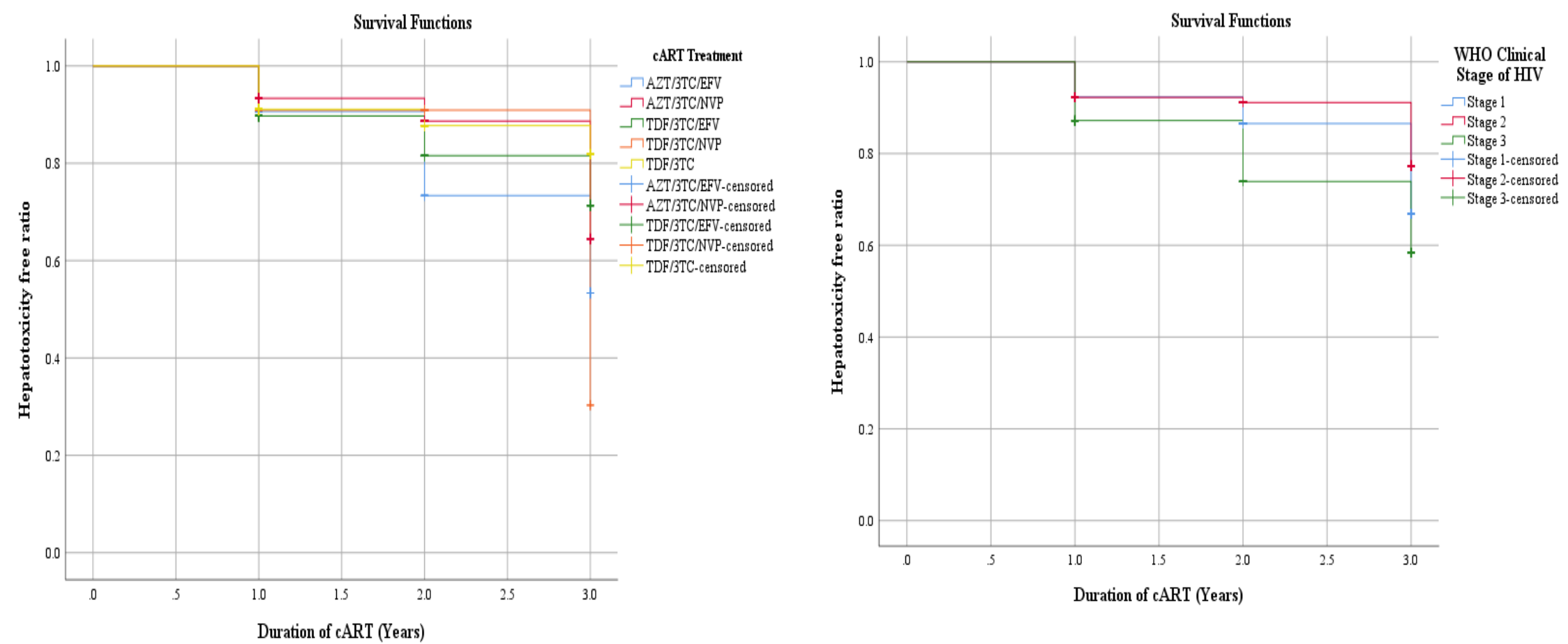

Figure 2: Kaplan-Meier Survival curves of hepatotoxicity with respect to cART treatment groups and WHO Clinical stage 


\section{Discussion}

\section{General Characteristics}

Hepatotoxicity is one of the most common adverse drug reactions associated with HAART/cART in Persons Living withHIV/AIDS. This increases the mortality rate in PLWHIV, rather than the HIV infection itself.

As observed in this study, age difference is not a determinant factor for ALT or AST elevations. This is supported by studies reported in Africa [14, 36] and Zürich-Switzerland [37]which reported that age is not a risk factor for the development of hepatotoxicity in patients on cART/HAART.However, studies carried out elsewhere in Africa reported that age was significantly associated with drug-induced hepatotoxicity $[15,31]$. These differences could be due to the fact that more than $60 \%$ of our study participants were above 40 years of age.

In our study, many more femalesdevelopedhepatotoxicitywhen compared with males (Table 1).Our findings are similar to those of studiesreported in Fako-Cameroon[29, 30], elsewhere in Ethiopia[15, 31, 33] and in Milan-Italy[21].However, studies in Zürich-Switzerland [37], Tanzania [36] and Ethiopia [23], reported higher rates of hepatotoxicity amongmale than female patients on cART. These differences could be as a result of the fact that this study, weenrolled only HIV patients.

\section{Hepatotoxicity}

In the present study, the overall cART-induced hepatotoxicity among HIV-infected patients was $16.3 \%$, which waslower compared to the $42.4-54 \%$ reported in Cameroon[29, 38],20.1 - 32\% in Ethiopia [23, 32, 39], 25\% reported in Warsaw-Poland [12] and 19.7/100 person years in South Africa[28]. Our findings were higher compared to the 13.6\% reported in Fako-Cameroon[30], $11.5 \%$ in Ethiopia [33] and $7.8 \%$ in Tanzania[36]. However, our study is consistent with the $16 \%$ reported in Zürich-Switzerland[37] and Taiwan-China [40]and the $15-16.7 \%$ reported in 
Ethiopia[15, 31]. This could be explained by the fact that the present study did not include tuberculosis and tuberculosis/ HIV co-infected patients, neither did it include hepatitis B and C viral infections as well as co-infections.

The finding of this study indicated that ALT and AST related hepatotoxicity were $17.7 \%$ and $68 \%$ respectively. This was in line with the findings of a study reported in Ghana[14] and lower when compared to findings reported in Yaoundé-Cameroon [38].

\section{Predictors of hepatotoxicity}

We observed a relatively higher incidence of hepatotoxicity amongst case patients receiving TDF/3TC/EFV (21.1\%, $\mathrm{N}=57), \mathrm{AZT} / 3 \mathrm{TC} / \mathrm{EFV}(17.5 \%, \mathrm{~N}=57)$ and TDF/3TC/NVP $(12.3 \%, \mathrm{~N}=$ 57) compared to those on other treatment groups. Although there was no statistical association of cART treatment groups with hepatotoxicity, there were significant variations of the elevated transaminases with the cART treatment groups (Table 2$)$. The highest mean $(\bar{x} \pm \mathrm{SEM})$ elevations of both ALT $(39.13 \pm 2.87)$ and AST $(64.34 \pm 2.11)$ were observed in TDF/3TC/EFV treatment group (Table 2). These elevations were similar to those reported in Cameroon [29, 38] and in Ghana [14].

In this study, it was observed that the sex (male) and alcohol consumption were the independent predictors of cART-induced hepatotoxicity. The WHO clinical stage 2 of HIV, AZT/3TC/EFV regimen and cigarette smoking were significantly associated with hepatotoxicity (Table 3). Our finding of male being a predictor was in line with that of a study reported in Ethiopia [32] and different from females as reported in Ethiopia [23, 31]. Alcoholism as reported in this study was in line with alcoholism reported in London [16], Zürich [37], as well as concomitant administration of other drugs $[15,17,28]$. 


\section{Strengths and limitations of the study}

Strengths of the study: The data used was collected by experienced scientists, using laboratory forms and patients' records.

Limitations of the study: A limitation to the study was that it was a cross-sectional study collecting data on the dependent and independent variables at the same time. It equally did not consider the concomitant administration of other therapeutic agents; anti-malaria drugs, herbs, as well as smoking and alcohol intake.

\section{Conclusion}

In conclusion, cART-induced hepatotoxicity is incident amongst HIV-infected patients seeking health care in the Bali District Hospital, regardless of the cART treatment group. Allof these hepatotoxic events were not severe and had no clinical significance. The male sex and alcoholism were associated with a higher rate of liver injury. Prospective studies focusing on the effects of cART/ HAART on hepatitis in HIV-infected patients are needed to confirm our findings.Combined antiretroviral therapy is frequent and a major concern amongst Cameroonian HIV patients and regular monitoring of liver enzymes during early therapy is recommended for proper identification and management of cART-induced hepatotoxicity.

\section{Declarations}

\section{Ethical approval and consent to participate}

Ethical clearance was obtained from the North West Regional Delegation of Health and the Higher institute of Health Sciences of Bamenda University of Science and Technology (BUST)and was conducted in accordance with the Helsinki declaration [35]. An administrative clearance was obtained from the Director of the Bali District Hospital. 
Participation in the study was voluntary, and all participants signed informed consent.

\section{Competing interests}

The authors declare that they have no competing interests.

\section{Abbreviations}

3TC: Lamivudine, 95\% C.I: 95\% Confidence Interval, AIDS: Acquired Immune Deficiency Syndrome, ALT: Alanine Amino Transferase, ARV: Antiretroviral Therapy, AST: Aspartate Amino Transferase, AZT: Zidovudine, cART: Combined Antiretroviral Therapy, cART-Induced Hepatotoxicity: $\mathrm{CIH}, \mathrm{CD}^{+}$: Cluster of Differentiation-4+ $4^{+}$cells, EFV: Efavirenz, HR: Hazard Ratio, HA: Health Area, HAART: Highly Active Antiretroviral Therapy, HIV: Human Immunodeficiency Virus, N(NRTI): Non (Nucleoside reverse transcriptase inhibitor), OR: Odds Ratio, $p$ : Significance value, VL: Viral Load, WHO: World Health Organisation, $\chi^{2}$ : Chi square.

\section{Acknowledgments}

Special thanks to our study participants, without whom this study would have been fruitless.

We cannot underestimate the collaboration of our friends, colleagues and the Laboratory staff of Bali District Hospital, Bamenda, Cameroon for their immense support towards the realization of this work.

\section{Authors' contributions}

YEN, FNC and NI conceived and designed the study; YEN, BSE, NGF and FN enrolled patients, collected specimens and performed the experiments; YEN and FNC curated the data and performed the statistical analyses; YEN, FNC and NI searched for literature and wrote the first draft of the manuscript; FNC, GMI and NI supervised the study; YEN and NI provided reagents, materials and analysis tools; YEN, FNC, GMI contributed to the discussion and scientific content; All authors contributed to the write up, reviewed the final draft, read and approved the final manuscript. 


\section{References}

1. Leboffe MJ, Pierce BE: A Photographic Atlas for the Microbiology Laboratory, 4 edn. United States of America: Morton Publishing Company; 2011.

2. Champoux JJ, Drew WL: Retroviruses, Human Immunodeficiency Virus, and Acquired Immunodeficiency Syndrome. In: Sherris Medical Microbiology: An Introduction to Infectious Diseases. Edited by Ryan KJ, Ray CG, Sheriss JC. New York McGraw-Hill Companies, Inc. Medical Publishing Division; 2004.

3. UNAIDS: Global AIDS update 2016. In.: UNAIDS; 2016.

4. WHO: Monitoring health for the SDGs, Sustainable Development Goals. In. Edited by World health statistics. Geneva, Swizaland: World Health Organization; 2017.

5. MOH: Cameroon Population-based HIV Impact Assessment (CAMPHIA). In. Edited by National AIDS Control Commission (NACC). Yaoundé: NACC; 2018.

6. WHO: Antiretroviral therapy for HIV infection in adults and adolescents: Recommendations for a public health approach. -2006 revision. In. Edited by Department of HIV/AIDS. Geneva, Switzerland: World Health Organization; 2006.

7. AIDSInfo: Guidelines for the Use of Antiretroviral Agents in Adults and Adolescents Living with HIV. Atlanta: A Working Group of the Offce of AIDS Research Advisory Council (OARAC); 2019.

8. MOH: National Guidelines on the Prevention and Management of HIV in Cameroon. In. Edited by The National AIDS Control Committee and National Tuberculosis Control Programme. Yaoundé, Cameroon: Ministry of Public Health; 2015.

9. Nsagha DS, Pokam BT, Assob JC, Njunda AL, Kibu OD, Tanue EA, Ayima CW, Weledji PE: HAART, DOTS and renal disease of patients co-infected with HIV/AIDS and TB in the South West Region of Cameroon. BMC Public Health 2015, 15:1040. 
10. Abah IO, Ncube NBQ, Bradley HA, Agbaji OO, Kanki P: Antiretroviral Therapyassociated Adverse Drug Reactions and their Effects on Virologic Failure- A Retrospective Cohort Study in Nigeria. Current HIV Research 2018, 16:436-446.

11. Anadol E, Lust K, Boesecke C, Schwarze-Zander C, Mohr R, Wasmuth JC, Rockstroh JK, Trebicka J: Exposure to previous cART is associated with significant liver fibrosis and cirrhosis in human immunodeficiency virus-infected patients. PLoS One 2018, 13(1):e0191118.

12. Pokorska-Śpiewak M, Stańska-Perka A, Popielska J, Ołdakowska A, Coupland U, Zawadka K, Szczepańska-Putz M, Marczyńska M: Prevalence and predictors of liver disease in HIV-infected children and adolescents. Sci Rep 2017, 7(12309).

13. Neukam K, Mira JA, Collado A, Rivero-Juarez A, Monje-Agudo P, Ruiz-Morales J, Rios MJ, Merino D, Tellez F, Perez-Camacho I et al: Liver Toxicity of Current Antiretroviral Regimens in HIV-Infected Patients with Chronic Viral Hepatitis in a Real-Life Setting: The HEPAVIR SEG-HEP Cohort. PLoS One 2016, 11(2):e0148104.

14. Osakunor DN, Obirikorang C, Fianu V, Asare I, Dakorah M: Hepatic Enzyme Alterations in HIV Patients on Antiretroviral Therapy: A Case-Control Study in a Hospital Setting in Ghana. PLoS One 2015, 10(8):e0134449.

15. Yimer G, Gry M, Amogne W, Makonnen E, Habtewold A, Petros Z, Aderaye G, SchuppeKoistinen I, Lindquist L, Aklillu E: Evaluation of patterns of liver toxicity in patients on antiretroviral and anti-tuberculosis drugs: a prospective four arm observational study in ethiopian patients. PLoS One 2014, 9(4):e94271.

16. Abbara A, Chitty S, Roe JK, Ghani R, Collin SM, Ritchie A, Kon OM, Dzvova J, Davidson H, Edwards TE et al: Drug-induced liver injury from antituberculous treatment: a retrospective study from a large TB centre in the UK. BMC Infect Dis 2017, 17(1):231. 
17. Araujo-Mariz C, Lopes EP, Acioli-Santos B, Maruza M, Montarroyos UR, Ximenes RA, Lacerda HR, Miranda-Filho Dde B, Albuquerque Mde F: Hepatotoxicity during Treatment for Tuberculosis in People Living with HIV/AIDS. PLoS One 2016, 11(6):e0157725.

18. Pozniak AL, Coyne KM, Miller RF, Lipman MCI, Freedman AR, Ormerod LP, Johnson MA, Collins S, Lucas SB, BHIVA Guidelines Subcommittee: British HIV Association guidelines for the treatment of TB/HIV coinfection 2011. HIV Med 2011, 12:517-524.

19. Aithal GP, Watkins PB, Andrade RJ, Larrey D, Molokhia M, Takikawa H, Hunt CM, Wilke RA, Avigan M, Kaplowitz $\mathrm{N}$ et al: Case definition and phenotype standardization in drug-induced liver injury. Clin Pharmacol Ther 2011, 89(6):806-815.

20. Reisler RB, Han C, Burman WJ: Grade 4 events are as important as AIDS events in the era of HAART. Journal of Acquire Immune Deficiency Syndrome 2003, 34(4):379-386.

21. Giacomelli A, Riva A, Falvella FS, Oreni ML, Cattaneo D, Cheli S, Renisi G, Di Cristo V, Lupo A, Clementi E et al: Clinical and genetic factors associated with increased risk of severe liver toxicity in a monocentric cohort of HIV positive patients receiving nevirapine-based antiretroviral therapy. BMC Infect Dis 2018, 18(556).

22. Björnsson ES: Hepatotoxicity by Drugs: The Most Common Implicated Agents. Int $J$ Mol Sci 2016, 17:224.

23. Yimer G, Ueda N, Habtewold A, Amogne W, Suda A, Riedel KD, Burhenne J, Aderaye G, Lindquist L, Makonnen E et al: Pharmacogenetic \& pharmacokinetic biomarker for efavirenz based ARV and rifampicin based anti-TB drug induced liver injury in TBHIV infected patients. PLoS One 2011, 6(12):e27810.

24. McGovern B: Hepatitis safety and HAART. J Int Assoc Physicians AIDS Care (Chic lll) 2004 2004, 3(Suppl 2):S24-40. 
25. Mancuso ME, Rumi MG, Aghemo A, Santagostino E, Puoti M, Coppola A, Colombo M, Mannucci PM: Hepatitis C virus/human immunodeficiency virus coinfection in hemophiliacs: high rates of sustained virologic response to pegylated interferon and ribavirin therapy. $J$ Thromb Haemost 2009, 7(12):1997-2005.

26. Yu YC, Mao YM, Chen CW, Chen JJ, Chen J, Cong WM, Ding Y, Duan ZP, Fu QC, Guo $\mathrm{XY}$ et al: CSH guidelines for the diagnosis and treatment of drug-induced liver injury. Hepatol Int 2017, 11(3):221-241.

27. Núñez M: Clinical syndromes and consequences of antiretroviral-related hepatotoxicity. Hepatology 2010, 52(3):1143-1155.

28. Hoffmann CJ, Charalambous S, Thio CL, Martin DJ, Pemba L, Fielding KL, Churchyard GJ, Chaisson RE, Grant AD: Hepatotoxicity in an African antiretroviral therapy cohort: the effect of tuberculosis and hepatitis B. AIDS 2007, 21(10):1301-1308.

29. Enoh JE, Cho FN, Manfo FP, Eyongabane SA, Achidi EA: Abnormal Levels of Liver Enzymes and Hepatotoxicity in HIV-Positive, TB, and HIV/TB-Coinfected Patients on Treatment in Fako Division, Southwest Region of Cameroon. BioMed Research International 2020.

30. Assob JCN, Nde PF, Nsagha DS, Njunda AL, Ngum NM, Ngowe NM: Incidence and Risk Factors of Anti-tuberculosis Drugs Induced Hepatotoxicity in HIV/AIDS Patients Attending the Limbe and Buea Regional Hospitals. J AIDS Clin Res 2014, 05(03).

31. Wondifraw BH, Birhanemeskel T, Mikiyas G, Gebrehawaria B, Wabe K, Belete B: Assessment of the effect of antiretroviral therapy on renal and liver functions among HIV-infected patients: a retrospective study. HIV/AIDS - Research and Palliative Care $2017,9$.

32. Shiferaw MB, Tulu KT, Zegeye AM, Wubante AA: Liver Enzymes Abnormalities among Highly Active Antiretroviral Therapy Experienced and HAART Naive HIV-1 Infected 
Patients at Debre Tabor Hospital, North West Ethiopia: A Comparative Cross-

Sectional Study. AIDS Res Treat 2016, 2016:1985452.

33. Hassen AA, Belachew T, Yami A, Ayen WY: Anti-tuberculosis drug induced

hepatotoxicity among TB/HIV co-infected patients at Jimma University Hospital,

Ethiopia: nested case-control study. PLoS One 2013, 8(5):e64622.

34. NIS: Demographic and Health survey and Multiple Indicators Cluster Survey DHS-

MICS 2011. In. Yaoundé, Cameroon: National Institute of Statistics; 2012.

35. Shrestha B, Dunn L: The Declaration of Helsinki on Medical Research involving Human

Subjects: A Review of Seventh Revision. Journal of Nepal Health Research Council 2019, 17(45):548-552.

36. Mugusi S, Ngaimisi E, Janabi M, Minzi O, Bakari M, Riedel KD, Burhenne J, Lindquist L, Mugusi F, Sandstrom E et al: Liver enzyme abnormalities and associated risk factors in HIV patients on efavirenz-based HAART with or without tuberculosis co-infection in Tanzania. PLoS One 2012, 7(7):e40180.

37. Kovari H, Ledergerber B, Battegay M, Rauch A, Hirschel B, Foguena AK, Vernazza P, Bernasconi E, Mueller NJ, Weber R: Incidence and Risk Factors for Chronic Elevation of Alanine Aminotransferase Levels in HIV-Infected Persons without Hepatitis B or C Virus Co-Infection. Clin Infect Dis 2010, 50(4):502-511.

38. Kamga HLF, Assob JCN, Nde PF, Weldeji P, Ndikvu CP: The effects of antiretroviral treatment on liver function enzymes among HIV infected out patients attending the central hospital of Yaoundé Cameron. African Journal of Clinical and Experimental Microbiology 2010, 11(3):174-178.

39. Mulu W, Gidey B, Chernet A, Alem G, Abera B: Hepatotoxicity and associated risk factors in HIV-infected patients receiving antiretroviral therapy at Felege Hiwot Referral Hospital, Bahirda, Ethiopia. Ethiopian Journal of Health Sciences 2013, 23(3). 
bioRxiv preprint doi: https://doi.org/10.1101/2020.11.16.384339; this version posted November 16,2020 . The copyright holder for this preprint (which was not certified by peer review) is the author/funder, who has granted bioRxiv a license to display the preprint in perpetuity. It is made available under aCC-BY 4.0 International license.

40. Chou C-M, Tsai H-C, Wu K-S, Sy C-L, Chen JK, Chen YS, Lee SS-J: Highly active antiretroviral therapy-related hepatotoxicity in human immunodeficiency virus and hepatitis $\mathbf{C}$ virus co-infected patients with advanced liver fibrosis in Taiwan. Journal of Microbiology, Immunology and Infection 2016, 49:546-553. 